Editorial

\title{
Working together, increasing responsiveness and capacity building
}

Mahmoud Fikri ${ }^{1}$

On 24 January 2017, the 140th Session of the WHO Executive Board awarded me the honour of the appointment of Regional Director for the WHO Regional Office for the Eastern Mediterranean (EMRO), following a nomination by the Regional Committee for the Eastern Mediterranean (1). Since then, WHO Director General Dr Margaret Chan has been very supportive in giving me the opportunity to visit other Regional Offices under her guidance and direction. For the last five years EMRO has been led by Dr Ala Alwan and I would like to extend my sincere gratitude for his efforts in leading EMRO with competence and confidence.

During my statement to the Regional Committee in October 2016, I highlighted a number of regional challenges and suggested certain priorities to be taken into account in order to enable the Region to overcome these difficulties. I repeat my statement then that, "I hereby commit to act immediately and work even harder to introduce the proposed changes I advocated for, and all possible efforts must be mobilized and made available immediately in order to find appropriate solutions to these challenges; actions must start now. Here, I promise to put WHO on the front line to provide the necessary technical and managerial support to all Member States in the Region by working with them closely. I believe no tangible changes can be made if we are far away from the areas where these changes are needed most."
WHO has the technical ability and is equipped to respond to the needs of countries. The General Programme of Work 2014-2019 and the detailed biennium programme budget identify major priority areas for countries that WHO supports within its technical work (2). The vision is to fulfill requirements and further strengthen and develop the five top priority areas, which will be the main agenda during my term as Regional Director. These include emergency preparedness, strengthening health systems, controlling communicable and noncommunicable diseases, reducing maternal and child mortality, and effectively addressing inequities through focusing on social determinants of health (3).

During my term, greater emphasis will be placed on specific areas that are negatively affecting the Region, including the eradication of poliomyelitis, which remains a top priority and continues the achievements made over the past five years $(3,4)$. In addition, it is my aim to achieve progress towards Universal Health Coverage in all countries of the Region in line with the Sustainable Development Goals (SDG) $(5,6)$. This will represent a rich platform for planning and implementing health programmes in the coming five years. Together we will be working on supporting human resources development and capacity building under a leadership programme. EMRO and country offices can expect to work in a more responsive manner to address the needs of Member States through better utilization of available resources, recruitment of qualified staff and ensuring a transparent and a competent working environment. My commitment is to increase the delegation of authority to technical staff in the Regional Office and at the country level in order to encourage competition, creativity, innovation and excellence. In addition, it is my duty to exert all possible efforts to improve internal coordination within WHO to act as one entity across all levels of the Organization. All possible opportunities will be sought towards working together with other United Nations (UN) agencies, developmental partners and non-governmental organizations on related matters such as SDGs and the UN Political Declaration on Noncommunicable Diseases, international health regulations, various global strategies plans and frameworks (7).

I commit myself to forging stronger cooperation with all WHO Member States and dedicate my experience, knowledge and efforts to serve all countries equally. Finally, I would like to thank all WHO staff, the WHO Regional Committee of the Eastern Mediterranean and the Executive board for their work and look forward to a fruitful future together. 


\section{References}

1. World Health Organization.Mahmoud Fikri appointed as Regional Director for the WHO Eastern Mediterranean Region. Geneva: World Health Organization; 2017 (http://www.who. $\mathrm{int/mediacentre/news/notes/2017/Fikri-director-emro/en/,}$ accessed 26 February 2017).

2. World Health Organization. Twelfth General Programme of Work: Not merely the absence of disease (2014-2019). Geneva: World Health Organization; 2017 (http://apps.who.int/iris/ bitstream/10665/112792/1/GPW_2014-2019_eng.pdf, accessed 1 March 2017).

3. Alwan A. Five years in action: strengthening public health in the Region and beyond. East Mediterr Health J. 2016; 22(12):857-9 (http://www.emro.who.int/emhj-volume-22-2016/volume22-issue-12/five-years-in-action-strengthening-public-healthin-the-eastern-mediterranean-region-and-beyond.html, accessed 1 March 2017).

4. World Health Organization.Poliomyelitis Fact Sheet. Geneva: World Health Organization; 2016(http://www.who.int/mediacentre/factsheets/fs114/en/, accessed 1 March 2017).
5. United Nations Development Programme (UNDP).Goal 3 targets. Geneva: UNDP; 2016 (http://www.undp.org/content/undp/en/home/sustainable-development-goals/goal3-good-health-and-well-being/targets/, accessed 1 March 2017).

6. World Health Organization. Universal health coverage - Sustainable Development Goal 3: Health. Geneva: World Health Organization; 2017(http://www.who.int/universal_health_ coverage/en/, accessed 1 March 2017).

7. World Health Organization. Framework for action to implement the United Nations Political Declaration on Noncommunicable Diseases, including indicators to assess country progress by 2018. Cairo: WHO Regional Office for the Eastern Mediterranean; 2016 (http://www.emro.who.int/images/ stories/ncd/NCD_framework_for_action_-_updated_2014_-EN_D.pdf?ua=1, accessed 1 March 2017). 